\title{
Dr Boyden at the bedside
}

\section{Vernon Reynolds}

Western Civilization in Biological Perspective: Patterns in Biohistory. By Stephen Boyden. Clarendon: 1987. Pp.370. £32.50, \$55.

CAN the ills of our Western way of life be diagnosed? Is our civilization healthy? Has the past produced a vigorous child or a many-headed monster? For Stephen Boyden, our conventional history is inadequate to the task of describing and evaluating modern society; he relies on 'biohistory'. This generates a different kind of understanding, 'biosophy', which is rooted in nature, and sees man evolving from a state of nature to a state of culture. Culture is our human adaptation. In the first place human beings adapted culturally to prevailing (natural) ecological circumstances, but soon undesirable consequences became apparent and we had to make further cultural adaptations. This is a continuing process - today's anti-pollution laws, for instance, are adaptations to unwanted fall-out from earlier cultural adaptations.

\section{This is a great book, and an exciting book. . . readable, worth reading and enlightening. Sir Karl Popper}

\section{Cosmology, Physics \& Philosophy}

\section{by \\ Prof Ben Gal-Or}

\section{A Master Piece! \\ Indian Journal of Physics}

\section{... shines a welcome light in some dark corners of science.}

\section{New Scientist}

\section{2nd Edition}

Springer-Verlag, 1987

1755 th Ave.,

N.Y., 10010.

Reader Service No.7
This is Boyden's theme, as later chapters show, but the first half of the book consists of biohistory. This is divided into three stages -- primaeval, early farming and early urban - which lead on to the high-energy stage, the one in which we now live.

Much of what Boyden relates in this book is by no means new. What is new is the synthesis of ideas. It is only at the end, in the appendix, that one realizes what the author is up to. He writes: "My colleagues and I have found check-lists to be an invaluable device for ensuring that . . . all important and relevant variables, concepts, and principles are taken into account in the biohistorical assessment of human situations" (p.325). A series of check-lists follows. "Biohistorical assessment" - in other words, diagnosis of our modern society - is Boyden's aim. He finds it alive but pervasively sick.

In evaluating this enterprise, the first question must be whether a better understanding of our particular kind of modern society can result from study and knowledge of humanity's primaeval huntergatherer, early farming and early urban past. Those past phases have given rise not only to Western civilization but to all nonWestern ones as well.

Toynbee, briefly mentioned by Boyden, argued that each civilization developed because it took up a certain challenge, which set the limits for endeavour for its leaders and its people. Loss of confidence in the value of the challenge led to each civilization's decline and fall. Boyden's pages are not stocked by descriptions of the rise and fall of other civilizations, nor could this one book possibly have taken on more than it has already. But other civilizations have arisen and flourished mightily, and there is much left to be explored in the precise ways that these have developed their particular preoccupations. Spiritual ideas have in the past often been paramount in the minds of the élites controlling civilizations - witness Ancient Egypt - and perhaps the fact that ours is a civilization whose leaders' preoccupations are almost entirely secular may be important in understanding what is especially distinctive about our own day and age.

Darlington, surprisingly, gets no mention. His book The Evolution of Man and Society, like Boyden's, tries to understand history and ourselves from an evolutionary perspective. His work differs in approach from Boyden's for it is replete with descriptions and insights into the different trajectories of peoples, cultures and societies all over the world. It has none of Boyden's competence in ecology, none of his awareness of the hazards to health and to the well-being of our own kind of civilization. But it is comparative, and it does try to show how, by taking one path, or solving one problem, societies and civilizations have succeeded in making certain advances while, simultaneously, sowing the seeds of their own destruction.

Biohistory eschews the fine detail of time and place. Instead we have "evodeviant" cultures, always in danger of worsening life because of the mistakes they make with respect to what is natural for man. This is something of a blanket critique and it runs a very particular danger: what seems to be harmless is accepted as natural, and what is harmful is seen as unnatural. For instance, we are told that the most natural diet - raw fruit and vegetables with a little cooked lean meat - is also the healthiest one. This certainly seems to fit with modern Western dietary ideology, but we need far better evidence than is currently available about the health-related effects of all the varied diets that exist world-wide in order to be sure what is optimal.

What we have in this book is an evolutionary backcloth followed by an ecological critique of Western society. The ideas are distilled and wise, if at times rather bland, and one is left feeling that this is an important strand of modern thinking. It is clear that we are paying a price for our way of life, both individually in terms of psychic health, and ecologically in terms of the continuing damage we inflict on the biosphere.

Boyden ends with a look to the future, in which he concludes that

society must be organized so that the life conditions of people are health-promoting, with regard both to material aspects of experience, such as diet, air quality, and housing, and to behavioural, psychosocial, and intangible aspects which affect, for example, physical fitness, sense of personal involvement, sense of belonging, and sense of self-fulfilment [p.313].

How this might happen is less evident. "Clearly, some new element has to be brought into the adaptive process", something that "transcends national, political, religious, occupational, and racial boundaries" (p.314). This is not an avowal of optimism. Unlike Konrad Lonrenz, who after laying out our innate inclinations to go astray was wont to end with a fervent message of hope, Boyden in his final pages reverts to "phylogenetic ineptitudes", "behavioural deficiencies" and the "flaming moth" principle. Certainly he has catalogued Western civilization's mistakes, and his book is a useful reminder to those of us who benefit most from its wealth that the price we are already paying could escalate into a disaster.

Vernon Reynolds is a Lecturer in the Department of Biological Anthropology, University of Oxford, 58 Banbury Road, Oxford OX2 6QS, UK 